\title{
Erythromelalgia: Pain and Redness of the Feet after Warm Water Exposure
}

\author{
Sho Fukui ${ }^{1,2}$, Hiromichi Tamaki ${ }^{1}$ and Masato Okada ${ }^{1}$
}

Key words: Erythromelalgia, erythema, pain, skin

\author{
(Intern Med Advance Publication) \\ (DOI: 10.2169/internalmedicine.8038-21)
}
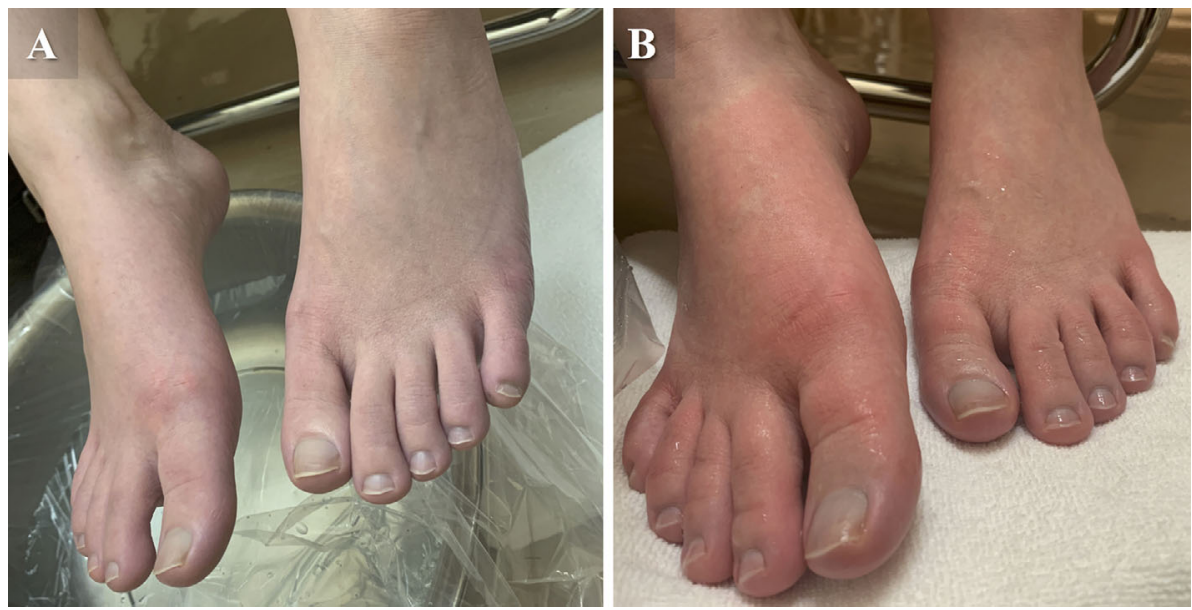

Picture.

A 39-year-old woman presented with pain in distal extremities. The patient had tingling pain, particularly in the lower legs, with heat sensation and redness, which was typically exacerbated in a hot environment and continued for hours. Since the patient had no pain with an examination of the feet showing normal findings (Picture A), we soaked her feet in warm water. Consequently, the patient developed strong foot pain 10 seconds after exposure, with markedly swollen, red-colored feet (Picture B). The symptoms subsided within half an hour following cold water exposure. As further examinations revealed no findings for myeloproliferative, autoimmune or other underlying diseases, a diagnosis of idiopathic erythromelalgia was made. She was advised to avoid heat exposure and misoprostol relieved her symptoms.

Erythromelalgia is a rare, poorly understood condition characterized by intermittently affected, painful extremities with erythema caused by dysfunction in the vascular dynam- ics, which worsens with heat exposure (1). Erythromelalgia should be actively considered as symptoms may only be apparent only during a flare in mild cases.

The authors state that they have no Conflict of Interest (COI).

Author contributions: SF cared for the patient with assistance from HT and MO. SF obtained publication consent from the patient. SF drafted the manuscript, and HT and MO revised the draft critically. All authors approved the final version of the manuscript and agree to be accountable for all aspects of the work.

Informed consent: The patient was informed of the contents of this article and provided their consent for publication.

Ethical approval: The requirement of ethical approval was waived due to the nature of this manuscript

Source of funding: This report was made without any funding.

${ }^{1}$ Immuno-Rheumatology Center, St. Luke's International Hospital, Japan and ${ }^{2}$ Center for Clinical Epidemiology, St. Luke's International University, Japan

Received: May 27, 2021; Accepted: June 3, 2021; Advance Publication by J-STAGE: July 17, 2021

Correspondence to Dr. Sho Fukui, fukusho@luke.ac.jp 


\section{Reference}

1. Mann N, King T, Murphy R. Review of primary and secondary erythromelalgia. Clinical and Experimental Dermatology 44: 477482, 2019.
The Internal Medicine is an Open Access journal distributed under the Creative Commons Attribution-NonCommercial-NoDerivatives 4.0 International License. To view the details of this license, please visit (https://creativecommons.org/licenses/ by-nc-nd/4.0/).

(C) The Japanese Society of Internal Medicine Intern Med Advance Publication 